\title{
Reverse Logistics: Network Design Based on Life Cycle Assessment
}

\author{
Joanna Daaboul", Julien Le Duigou, Diana Penciuc, and Benoît Eynard \\ Université de Technologie de Compiègne \\ Rue du Dr Schweitzer, Compiègne, 60200 Cedex, France \\ \{joanna.daaboul, julien.le-duigou, diana.penciuc, \\ benoit.eynard\}@utc.fr
}

\begin{abstract}
When aiming to a more sustainable world, enterprises such as aircraft and automobile industries are highly interested in light weight components and solutions. Of these solutions are aluminum wrought alloys that offer high potentials for dramatic weight reduction of structural parts. Nevertheless, the production of virgin aluminum is, however, highly energy consuming. Hence, and in SuPLight project, we are interested in recycled aluminum. The aim of this project is to address new industrial models for sustainable light weight solutions - with recycling in high-end structural components based on wrought alloys. In this article we address the issue of designing the reverse logistics chain assuring the needed volume of recycled aluminum for the production of L-shaped Front Lower Control Arms for personal cars.
\end{abstract}

Keywords: Reversed logistics design, LCA, wrought aluminum.

\section{$1 \quad$ Introduction}

Until recently, Reverse Logistics (RL) was not given a great deal of attention in organizations. Actually, implementing RL programs to reduce, reuse, and recycle wastes from distribution and other processes generates tangible and intangible value and can lead to better corporate image [1]. Its main drivers are legislations and directives, consumer awareness and social responsibilities towards environment [2-4]. Another motivating driver of RL is economic factors. RL can generate profits by reselling valuable components or products [5]. Reverse logistics is of high importance for aluminum based products, since the production of virgin aluminum is highly energy consuming.

RL operations and chains they support are significantly more complex than traditional manufacturing supply chains [6-8]. Therefore, and similarly to how companies develop efficient logistics processes for new goods, it is necessary to plan operations for returned goods, taking into consideration that the processes are most probably quite different from those defined for forward distribution [9]. RL is not a symmetric

\footnotetext{
* Corresponding author.
} 
picture of forward distribution [10] and requires different management and planning approaches. For example, it is difficult, in the case of RL, to estimate supply-related parameters such as the unit operational costs directly from reported statistical data.

In this article we are interested in designing an effective reverse logistics network for the L-shaped Front Lower Control Arms (FLCA) (Figure 1) for personal cars [11] within the SuPLight ${ }^{1}$ project which is a multidisciplinary research project, combining physics at the atomic scale level, metallurgy, continuum mechanics, structural mechanics, optimization algorithms, tolerance analysis, life cycle analysis, manufacturing and business modeling. The project addresses new industrial models for sustainable light weight solutions - with $75 \%$ recycling in high-end structural components based on aluminum wrought alloys.

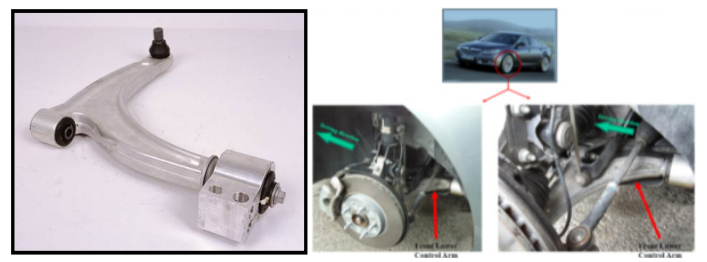

Fig. 1. Front Lower Control Arm (FLCA) [6]

In our case study we are interested in designing the reverse logistics with the following characteristics:

1. The RL network should be environmental friendly as much as possible

2. The different facilities (collection locations, remanufacturing facilities, etc) are not necessarily owned by one company

3. The reverse flow has different sources and might have depending on these sources different disposal routes (reselling, remanufacturing, recycling, etc).

\section{$2 \quad$ Related Works}

Designing a reverse logistics network is usually achieved via mathematical programming. Generally a mixed-integer linear programming model is generated in order to define the optimum collection locations and recycling factories [12]. After analyzing the literature we concluded the following:

The literature presents three main types of networks: Forward logistics, reverse logistics, and forward/reverse logistics [12]. We are only considering the reverse logistics network.

The most considered decision criterion is the total cost of the network [13-17], followed by the service level [18], and the generated profit [12]. In the recent literature review in [12], the only objectives considered in RL or forward/reverse chain design are: cost, profit, responsiveness (Service level), source balance, and quality. [19]

\footnotetext{
${ }^{1}$ http: / /www.suplight-eu.org /
} 
propose a generic model for reverse logistics design considering only costs as decision criteria. [20] propose a two-stage stochastic programming model for multiperiod reverse logistics network design with as main decision criteria the different investment and operational costs. [21] consider the environmental regulations as a constraint to their decision model but not as decision criteria. [22] also proposed a mixed integer linear programming model for supply chain planning including reverse logistics activities. Yet they consider the expected net present value (ENPV), as the decision criterion. In our case, we are interested not only in the total cost of the network, but also in the environmental impact of the network as a main decision criterion. Therefore, the remanufacturing and recycling processes impacts on environmental performance of the network need to be considered.

The main decisions of the models are: location/allocation of facilities and transportation values [13-18]. Moreover, most of the works found in the literature consider the network design problem with collection, sorting, and disposal facilities owned by one company which is collecting the reverse flow and reusing it. But in many cases, reverse logistics do not only include facilities owned by the company itself, but facilities owned by other partners in the chain. In this case, designing the best RL network consists of 2 main problems: choosing the partner and optimizing the whole network formed of facilities owned by different partners. Since reverse logistics are a part of green supply chains and since we are interested in the environmental performance of the network, the choice of the partners is to be made based on their impact not only on the total cost of the network, but also on the environmental performance of the network.

Most of the works found in the literature consider mainly the remanufacturing option of the disposal step [13], [14], [16-18] and only few consider the recycling option of the disposal step such as [15], [23]. But in our case, we are interested in recycling the reverse flow as well as remanufacturing it. In other words, we are interested in different sources of reverse flows which have each different disposal route.

\section{A Framework for the Design of Reverse Logistics}

\subsection{Network Design Method}

Considering our analysis of the literature and based on our specific needs, a life cycle approach seems adequate to analyze the performance of the chosen network. It permits assessing the environmental performance of the RL network alone and also its impact on the whole life cycle assessment of the product. Thus, we propose a comparison based method formed of 5 main steps described in Figure 2.

\section{Step 1: Context definition}

In this step, the company and the product (s) are described.

\section{Step 2: Parameters definition}

Since we are interested in defining the different partners in the RL network as well as the environmental performance of the different processes in the network, a framework linking the processes to the partners was developed. 


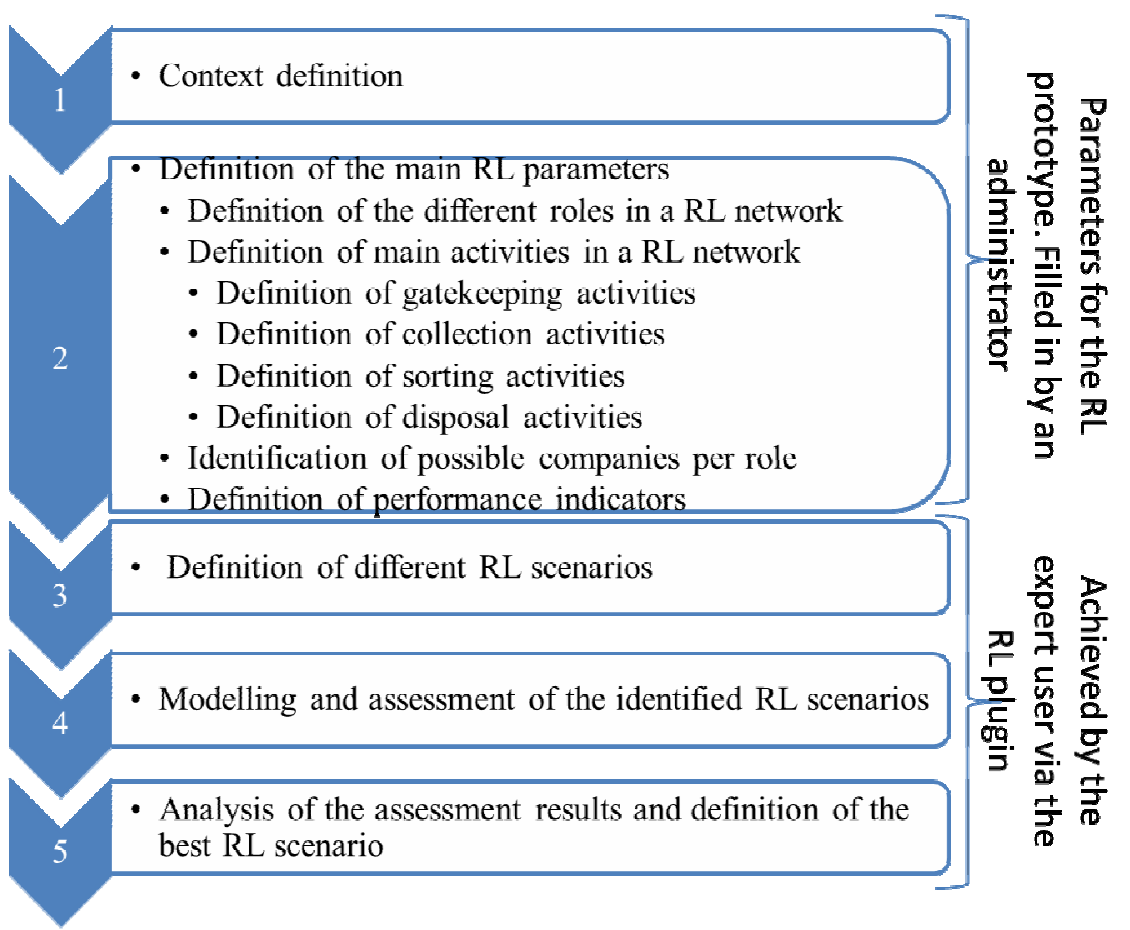

Fig. 2. Proposed method for reverse logistics network design

According to the literature, reverse logistics is formed of 4 main phases: gatekeeping, collection, sorting, and disposal [23-26]. The disposal step includes landfilling, remanufacturing, recycling and reselling. For each phase the set of activities to be achieved was identified based on literature analysis. Nevertheless, these activities differ between the design stage and the implementation (execution) stage. Thus, the differentiation between these activities was made and a framework based on design and implementation stages is proposed and presented in Figure 3.

The parameters definition consists of identifying the different roles in an RL chain, the responsibilities and activities per role, the requirements for these activities, and the performance indicators per requirement per activity. Four roles were identified: collector, sorter, disposer and the end collector of the reversed flow. A same partner may have more than one role. For each of these roles, the responsibilities and activities were identified for design and implementation stages based on the previously presented framework. These activities are at a macro level and need to be detailed at a micro level but for specific cases or products.

The requirements per activity are case dependent. Most of it depends on the type of the product. The recycling processes for example differ based on the product type. Whereas the general performance indicators are: Total cost of the network including cost of transportation, facilities, purchasing, activities, and stock, Total emission of 


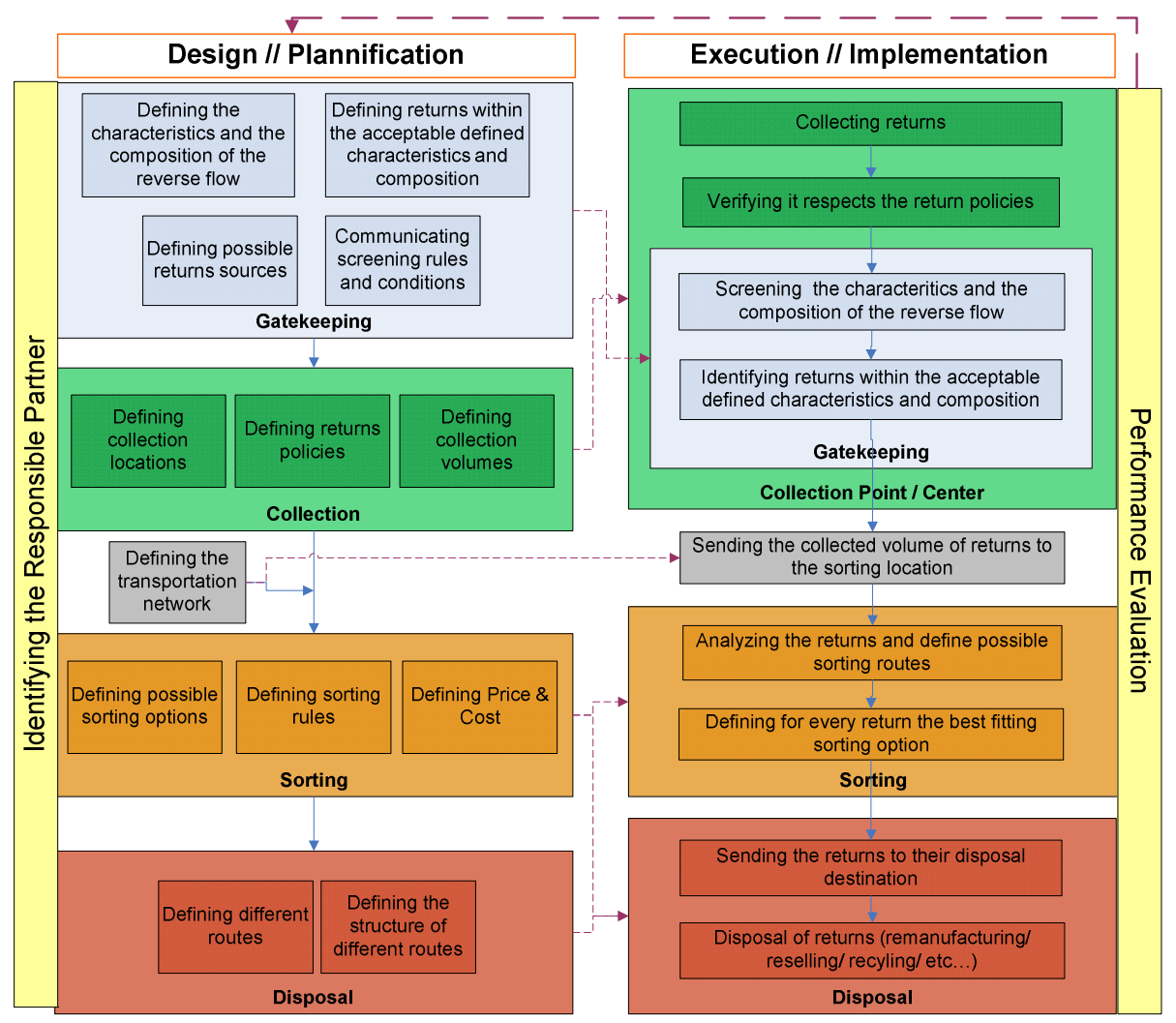

Fig. 3. Reverse Logistics Framework

$\mathrm{CO} 2$, an aggregation of main used life cycle assessment indicators such as carbon footprint of product, energy related indicators, chemicals used, PFC/GHG emissions, fresh water consumption, use of renewable/nonrenewable energy, and recycling related indicators such as the amount of recycled material (in our case it is aluminum), the collection quota CQ (the quantity of secondary material, which is recovered by collection systems, related to the total quantity of used products), and the technical recycling quota RQ (it is the relation between the remelted and the collected quantity and describes the yield of technical processes) [27].

Moreover, in step 2, case dependent parameters are identified. These are the candidate companies for playing one or more roles in the RL network. For each company a description sheet is filled contating information on the company, some performance indicators, and constraints such as minimum quantity of reverse flow, replenishement lead time, etc.

\section{Step 3: Scenarios definition}

The scenario definition is achieved by the expert user in one of 3 ways: 
1. Defining any RL network scenario, by choosing for each role one or more companies as well as the quantity of reverse flow and then by choosing the routes between these companies.

2. Defining the RL network step by step, using decision criteria per role. In this case, and for every role, the user may ask to identify the best company based on many decision criteria, such as distance, cost, processes used, labels, reverse flow quality, etc. This option is based on the Analytical Hierarchy Process (AHP). The steps that need to be followed in this option are described in figure 4. AHP is the most used decision support system for supplier selection [28]. This technique which was developed by Thomas L. Saaty [29] relies on the expertise of the user in order to generate the weights of attributes. It is based on the comparison of pairs of options and criteria. It has found widespread application in decision-making problems, involving multiple criteria in systems of many levels [30]. Its main advantages are:

- consideration of non-tangible subjective attributes,

o ability to structure a complex problem, multi-criteria, multi-person and multi-period hierarchically,

o capability to investigate each level of the hierarchy separately, and to combine the results as the analysis progresses.

o binary comparison of elements (alternatives, criteria and subcriteria),

○ ease of its IT support.

\begin{tabular}{l}
\hline$U$ Choose a specific role of the RL network \\
\hline$U$
\end{tabular}

Legende: $\mathrm{U}=$ User ; $\mathrm{P}=$ Plugin

Fig. 4. Steps to use the multi-criteria decision aid option 
3. Defining the optimal network based on the most used objective: the total cost using the optimisation option of the prototype. This option is a work-inprogress.

The user may choose many scenarios as desired and compare their performance in steps $4 \& 5$. In other words, the user may compare on the basis of all environmental and economic criterias the optimal scenario (based on cost only) with scenarios built with the decision aid option and with any other scenario built by the user alone without any aid of the system.

\section{Steps 4 and 5: Assessment of RL scenarios and results analysis}

After one or more scenarios are chosen, the different performance indicators are calculated. A comparision between the scenario is provided.

The evaluation of the RL network is achieved via a life cycle assessment software (SimaPro) [31]. This is possible within the Suplight project which aims at providing collaborative platform [32] allowing the communication and exchange of information between different software of which the Life Cycle Assessment software (LCA) and the RL demonstrator.

After the life cycle assesment of the different RL scenarios is received from the LCA software, a full analysis combing this assessment and the one achieved via the RL prototype (total cost of the network, quantity of recycled material, etc.) is provided to the user. A comparison of all created RL scenarios is then delivered to the user.

\subsection{Reverse Logistics Prototype}

The proposed framework was the basis of the development of the software prototype illustrating our method. It has been designed with a flexible architecture in order to

(*) localhost:8080/RLPlugin/inder.html

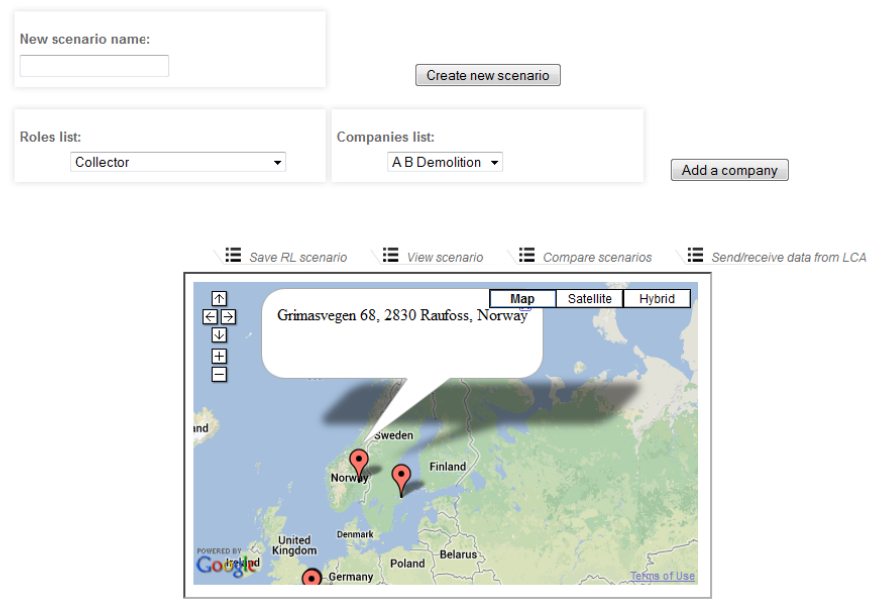

Fig. 5. RL Prototype main page 
allow portability and interoperability with any external application. The software prototype implementation is based on the MVC software architecture pattern, using HTML5 and CSS to create the view and for the application logic the JAX-RS Java API for RESTful web services which are controlled by JavaScript (JQuery).

The RL prototype is focused on RL scenario definition allowing the user to: choose the partners of the RL chain and their roles and visualize them on a map; define RL routes -a single route is characterized by flow and transportation data (a flow type and quantity exchanged between two partners, transportation mean and distance)-; visualize the summary of the created scenario and display LCA indicators for the current scenario. The total cost is computed for each route. Google services are used for automatic distance calculation and map display based on data provided by the user. The prototype main page and the route definition interface are presented in Figures 5 and 6 respectively. On the main page the prototype shows the RL scenario on a map with a description of the different routes including the nodes names (companies' names) with the type of reverse flow, quantity of flow, transportation mode and distance between the two nodes. The different enterprises or facilities chosen for the RL chain are presented on the map. This map is dynamic and shows the chosen facility locations or the chosen suppliers as well as all related costs. This map serves only as a visualization tool for the chosen scenario.

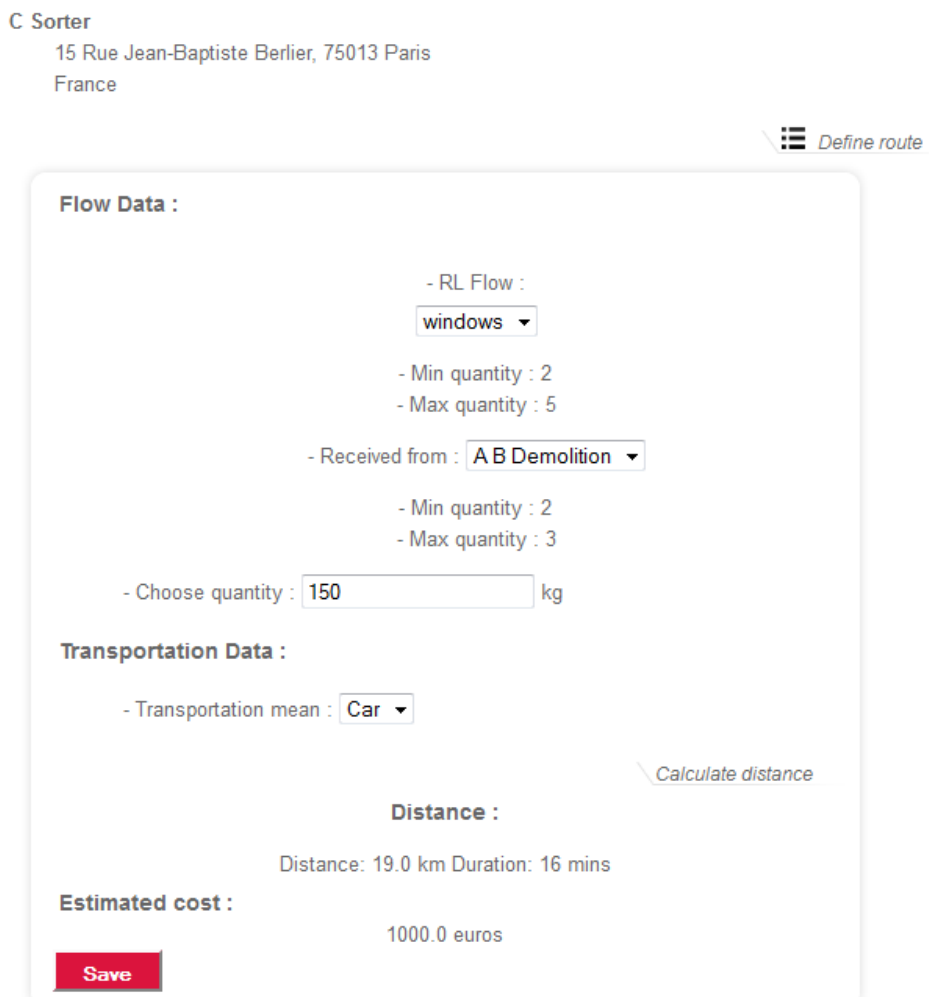

Fig. 6. Route definition interface of the RL prototype 
This prototype is not intended for advanced planning of a supply chain such as APS software (Advanced Planning and Scheduling). But its main function is to provide a support for decision making in designing a reverse logistics chain. Even though APS software may provide "What if" analysis, it doesn't offer a decision aid method such as AHP, nor does it provide the optimal RL chain among all possible scenarios; it permits only to compare between manually created scenarios. The use of the proposed demonstrator doesn't eliminate the need to use APS software which is necessary to manage a RL network. The demonstrator may be considered as a plug-in for APS software.

\section{Conclusion and Perspectives}

In this article we presented a framework for designing an RL network based on life cycle assessment. We are interested in identifying the partners of the network and the routes connecting them based on the total cost of the network and its environmental performance as well. In the perspectives of the presented work is the achievement of the optimization option of the prototype as well as applying the method and testing the prototype in the LFCA case study in the Suplight project.

Acknowledgments. The authors would like to acknowledge the European Commission and the Picardie French Region for their financial support through the SuPlight FP7 Project (grant agreement $n^{\circ}$ 263302). We also wish to express our gratitude and appreciation to all the project partners for their contribution during the development of various ideas and concepts presented in this paper.

\section{References}

1. Carter, C.R., Ellram, L.M.: Reverse logistics: a review of the literature and framework for future investigation. Journal of Business Logistics 19(1), 85-102 (1998)

2. Ferrer, G., Ayres, R.: The impact of remanufacturing in the economy. Ecological Economics 32(3), 413-429 (2000)

3. Castell, A., Clift, R., France, C.: Extended producer responsibility policy in the European Union-a horse or a camel? Journal of Industrial Ecology 8(1-2), 4-7 (2004)

4. Ravi, V., Shankar, R.: Analysis of interactions among the barriers of reverse logistics. Technological Forecasting and Social Change 72(8), 1011-1029 (2005)

5. Toffel, M.W.: The growing strategic importance of end-of-life product management. California Management Review 45(3), 102-129 (2003)

6. Amini, M.M., Retzlaff-Roberts, D., Bienstock, C.C.: Designing a reverse logistics operation for short cycle time repair services. International Journal of Production Economics 96(3), 367-380 (2005)

7. Rogers, D.S., Tibben-Lembke, R.S.: Going backwards: reverse logistics trends and practices. RLEC Press, Pittsburgh (1999)

8. Mitra, S.: Revenue management for remanufactured products. Omega 35(5), 553-562 (2007) 
9. Stock, J., Speh, T., Shear, H.: Many happy (product) returns. Harvard Business Review 80(7), 16-18 (2002)

10. Fleischmann, M., van Wassenhove, L.N., van Nunen, J.A.E.E., van der Laan, E., Dekker, R., Bloemhof-Ruwaard, J.M.: Quantitative models for reverse logistics: a review. European Journal of Operational Research 103(1), 1-17 (1997)

11. SuPLight. Document Deliverable 1.5: SuPLight application scenarios. SuPLight, EU FP7 Project, No. 263302 (2012a)

12. Ramezani, R., Bashiri, M., Tavakkoli-Moghaddam, R.: A new multi-objective stochastic model for a forward/reverse logistic network design with responsiveness and quality level. Applied Mathematical Modelling 37, 328-344 (2013)

13. Min, H., Ko, C.S., Ko, H.J.: The spatial and temporal consolidation of returned products in a closed-loop supply chain network. Comput. Indus. Eng. 51, 309-320 (2006)

14. Üster, H., Easwaran, G., Akçali, E., Çetinkaya, S.: Benders decomposition with alternative multiple cuts for a multi-product closed-loop supply chain network design model. Naval Res. Logist. 54, 890-907 (2007)

15. Listes, O., Dekker, R.: A stochastic approach to a case study for product recovery network design. Eur. J. Oper. Res. 160, 268-287 (2005)

16. Demirel, O.N., Gökçen, H.: A mixed-integer programming model for remanufacturing in reverse logistics environment. Int. J. Adv. Manuf. Technol. 39(11-12), 1197-1206 (2008)

17. Pishvaee, M.R., Kianfar, K., Karimi, B.: Reverse logistics network design using simulated annealing. Int. J. Adv. Manuf. Technol. 47, 269-281 (2010)

18. Du, F., Evans, G.W.: A bi-objective reverse logistics network analysis for post-sale service. Comput. Oper. Res. 35, 2617-2634 (2008)

19. Zhou, Y., Wang, S.: Generic Model of Reverse Logistics Network Design. Journal of Transportation Systems Engineering and Information Technology 8(3), 71-78 (2008)

20. Lee, D.-H., Dong, M.: Dynamic network design for reverse logistics operations under uncertainty. Transportation Research Part E: Logistics and Transportation Review 45(1), 61$71(2009)$

21. Lambert, S., Riopel, D., Abdul-Kader, W.: A reverse logistics decisions conceptual framework. Computers \& Industrial Engineering 61(3), 561-581 (2011)

22. Cardoso, S.R., Barbosa-Póvoa, A.P.F.D., Relvas, S.: Design and planning of supply chains with integration of reverse logistics activities under demand uncertainty. European Journal of Operational Research 226(3), 436-451 (2013)

23. Wang, H.F., Hsu, H.W.: A closed-loop logistic model with a spanning-tree based genetic algorithm. Comput. Oper. Res. 37, 376-389 (2010)

24. Rogers, D.S., Tibben-Lembke, R.S.: Going backwards: Reverse logistics trends and practices. Reverse logistics executive council, Reno (1998)

25. Schwartz, B.: Reverse logistics strengthens supply chains. Transportation and Distribution 41(5), 95-100 (2000)

26. Stock, J.: Product returns/reverse logistics on Warehousing. WERC, Oak Brook (2004)

27. Quinkertz, R., Rombach, G., Liebig, D.: A scenario to optimise the energy demand of aluminium production depending on the recycling quota. Resources, Conservation and Recycling 33, 217-234 (2001)

28. Van der Rhee, B., Verma, R., Plaschka, G.: Understanding trade-offs in the supplier selection process: The role of flexibility, delivery, and value-added services/support. International Journal of Production Economics 120(1), 30-41 (2009)

29. Saaty, T.L.: The Analytic Hierarchy Process. McGraw- Hill, New York (1980) 
30. Liu, F.-H.F., Hai, H.L.: The voting analytic hierarchy process method for selecting supplier. International Journal of Production Economics 97, 308-317 (2005)

31. SuPlight, Deliverable 4.3: LCA/LCC tools for lightweight solutions. SuPLight, EU FP7 Project, No. 263302 (2013)

32. SuPLight, Deliverable 3.2: Generic framework for simulation-based optimization. SuPLight, EU FP7 Project, No. 263302 (2012) 